\title{
ASSISTED CONCEPTION AND RETINOPATHY OF PREMATURITY
}

\author{
M. McKIBBIN and T. R. DABBS \\ Leeds
}

\begin{abstract}
SUMMARY
This study was performed to assess the workload imposed by treatment for infertility on a retinopathy of prematurity (ROP) screening programme. We reviewed the records of all babies born between August 1991 and December 1994 as a result of treatment in the Assisted Conception Unit of this hospital, and of all babies screened for ROP over the same period. Of the babies born after assisted conception treatment, $20 \%$ fulfilled the ROP screening criteria. ROP of any stage was present in $23 \%$ of all the assisted conception babies screened. This group also accounted for a large proportion of those reaching stage 3 disease and of those requiring treatment.
\end{abstract}

The Assisted Conception Unit in this hospital ( $\mathrm{St}$ James's, Leeds) offers treatment for primary and secondary infertility and services include superovulation with gonadotrophins, intra-uterine insemination, embryo, egg and sperm donation, in vitro fertilisation (IVF) and intra-cytoplasmic sperm injection. These treatments are associated with a higher percentage of multiple pregnancies, which are often completed prematurely and are delivered of low birth weight babies. ${ }^{1.2}$ Following an observed increase in the total number of screening examinations performed in the hospital for retinopathy of prematurity (ROP), this study was carried out to ascertain the impact of assisted conception on the ROP screening programme.

\section{PATIENTS AND METHODS}

The records of all babies born between August 1991 and December 1994 who were screened for ROP in the Neonatal Unit for the hospital, and the records of their mothers, were reviewed. Details of the birth data and examination findings were recorded for all the babies screened, and the number of pregnancies

Correspondence to: Mr M. McKibbin, Department of Ophthalmology, St James's University Hospital, Beckett Street, Leeds LS9 7TF, UK. Fax: +44 (113) 2837054. resulting from assisted conception treatment was noted. For the same period of time, the gestational age (estimated from the day of ovulation, egg or embryo transfer) and birth weights were recorded for all the births born after treatment in the Assisted Conception Unit of the hospital. This information was obtained either directly from the women having successful treatment in the Unit, who are asked to provide details of the outcome of the pregnancy including the gestational age and birth weight of the babies born, or from the hospital labour ward records. From the two sets of information the impact of assisted conception on the screening for and incidence of ROP in the hospital was then examined.

\section{RESULTS}

Between August 1991 and December 1994 there were 16208 live births in the hospital and ROP screening was performed on 267. Assisted conception accounted for 44 of those screened, with 29 babies born as a result of treatment in the hospital's Assisted Conception Unit and 15 born after treatment in other units. Of all the babies screened, 79 had features of ROP of any stage. Stage 1 disease was present in 31 , stage 2 disease in 31 and stage 3 disease in 17, of whom 8 progressed to threshold disease and subsequently had treatment.

Birth data were available for 188 pregnancies resulting from treatment in the hospital's Assisted Conception Unit, and the resultant 291 babies born alive within the same period of time. There were 103 singletons, 67 sets of twins and 18 sets of triplets. IVF treatment accounted for 233 births.

Of the 291 babies born after infertility treatment in this hospital, 59 fulfilled the screening criteria for ROP. This group comprised 3 singleton births, 19 twin births and 37 triplet births. The average birth weight of this last group was $1194 \mathrm{~g}$ (range 460-2170 g) and the average gestational age was 29.6 weeks (range 26-33 weeks). Of the 42 babies born in this hospital, 5 died and 8 others were transferred to

Eye (1996) 10, 476-478 (C) 1996 Royal College of Ophthalmologists 
other hospitals or discharged before screening was to be performed. Screening data were available for 29 babies. Ten of these had ROP of any stage, and $3 \mathrm{had}$ stage 3 disease, with 2 of these subsequently having treatment after progressing to threshold disease.

\section{DISCUSSION}

The absolute and relative numbers of multiple births in England and Wales has been increasing over the last 20 years, especially among older women. ${ }^{3}$ In this hospital, multiple births accounted for an average $2.1 \%$ of all births between 1980 and 1989. Since then the percentage has increased steadily to $4.4 \%$ of all live births in 1994, following the opening of the Assisted Conception Unit in 1991 (Fig. 1). In the United States the number of twin and triplet births increased at twice and seven times the rate of singleton births respectively between 1973 and $1990 .{ }^{4}$ Most of this increase was the result of assisted conception. The multiple pregnancy rate is $1 \%$ for natural conceptions, between $5 \%$ and $20 \%$ for ovarian stimulation and $22 \%$ for in vitro fertilisation and embryo transfer (IVF). ${ }^{1,2}$ Of the 291 births resulting from infertility treatment in the Assisted Conception Unit of this hospital, there were 67 sets of twins and 18 sets of triplets, and the majority of these multiple births resulted from IVF.

Many of the babies born after assisted conception are premature and of low birth weight. This is mainly the result of the increased number of multiple births, and both the birth weight and the gestational age fall in direct relation to the multiplicity of the pregnancy. ${ }^{4,5}$ However, even singleton births resulting from assisted conception are more likely to be premature and of low birth weight than those conceived naturally. ${ }^{5,6}$ of all singleton births in England and Wales, $6 \%$ are premature (less than 37 weeks gestation) and $7 \%$ weigh less than $2500 \mathrm{~g}^{3}$ For singleton births resulting from assisted conception in England and Wales, $13 \%$ are born prematurely and $12 \%$ weigh less than 2500 g. $^{5}$

In this hospital babies are screened for ROP in

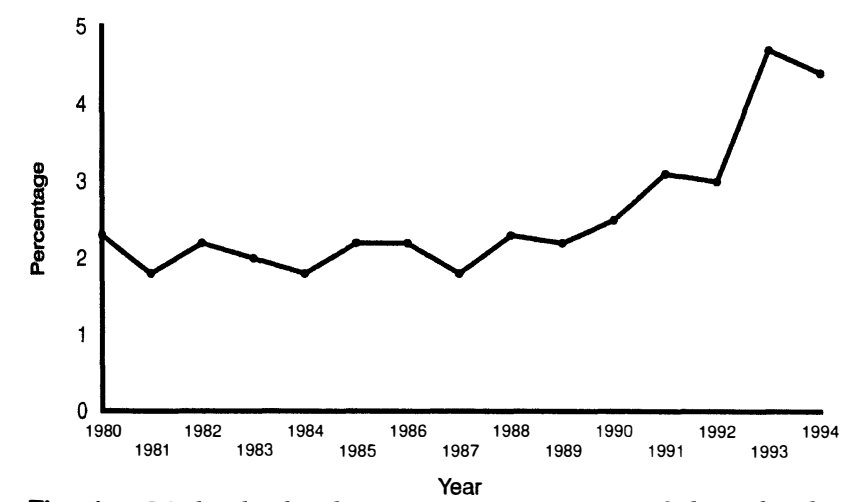

Fig. 1. Multiple births as a percentage of live births, 1980-1994. accordance with the guidelines of the Working Party of the British Association for Perinatal Medicine and the College of Ophthalmologists, which recommends screening infants born weighing less than $1500 \mathrm{~g}$ and/ or at less than 32 weeks gestation. ${ }^{7}$ There were 16208 live births in this hospital between August 1991 and December 1994, and 267 (1.65\%) were screened here. In other population-based studies, between $0.90 \%$ and $1.11 \%$ of all infants born fulfilled the same screening criteria. ${ }^{8-10}$ In contrast, screening was indicated for $20.3 \%$ of the babies born as a result of treatment in the Assisted Conception Unit of this hospital, while $16.5 \%$ of all the babies actually screened were born after assisted conception treatment in this hospital or in other units.

Of all the babies screened here, 79 (29.6\%) had features of ROP of any stage. Much of this was stage 1 or stage 2 disease, but 17 had stage 3 disease and 8 progressed to threshold disease. This compares with other series in which ROP was present in $9-66 \%$ of premature infants. ${ }^{9.11,12}$ (This large variation results mainly from the widely different screening criteria used.) In this study, of the 44 babies born as a result of assisted conception, $10(22.7 \%)$ had ROP of any stage and 3 had stage 3 disease, with 2 of these requiring treatment for threshold disease. Although assisted conception treatment accounted for a greater percentage of those babies reaching stage 3 disease and of those requiring treatment for threshold disease than might be expected, the numbers involved in this study are too small to be significant. The impact of assisted conception treatment appears to be entirely the result of the increased number of multiple births, as there was no significant difference in the incidence of ROP of any stage between those babies screened who were conceived naturally and those conceived after assisted conception. Since they are more likely to be born prematurely and of low birth weight, babies born after assisted conception treatment are also more likely to require screening and to have ROP than babies conceived naturally.

Infertility treatment is available in many other centres in the United Kingdom, with 66 centres licensed for IVF. ${ }^{13}$ The impact of assisted conception on neonatal services in the United Kingdom is well documented. ${ }^{6.14}$ It is the combination of the high multiple birth rate and the fact that all babies born as a result of assisted conception are more likely to be premature and of low birth weight than those conceived naturally that makes assisted conception so important. Attempts to reduce the perinatal morbidity and mortality primarily involve reducing the frequency of higher multiple births and prolonging the gestational age. However, women having assisted conception are older than those who conceive naturally and multiple pregnancies are more common in younger women. Furthermore, 
assisted conception is expensive and is not always available through the National Health Service. Many district health authorities are not prepared to fund infertility treatment, and even those which will provide funding often limit IVF treatment to women under 34 years and for one cycle only. Given the limited resources available, the temptation may be for infertile couples to accept the risk of a multiple pregnancy in an effort to ensure a successful pregnancy.

The impact of assisted conception on the screening for and the incidence of ROP has not been documented before. By increasing the size of the at-risk population, the effect has been to increase the workload of the screening programme and the incidence of ROP. In this study, $20 \%$ of the babies born as a result of treatment in an Assisted Conception Unit fulfilled the screening criteria for ROP and $16.5 \%$ of all the babies screened for ROP were born after assisted conception. Assisted conception treatment accounted for $18 \%$ of all those babies reaching stage 3 disease and for $25 \%$ of those reaching threshold disease and requiring treatment. With the demand for infertility treatment and the use of assisted conception increasing, it can only be expected that the additional workload imposed on ROP screening programmes will also increase in proportion.

Key words: Assisted conception, Retinopathy of prematurity, Screening.

\section{REFERENCES}

1. Ron-El R. Complications of ovulation induction. Baillieres Clin Obstet Gynaecol 1993;7:435-53.

2. Ezra Y, Shenker JG. Appraisal of in-vitro fertilization. Eur J Obstet Gynaecol Reprod Biol 1993;48:127-33.
3. Office of Population Censuses and Surveys. Birth statistics, England and Wales, London: HMSO (Series FM1), 1992.

4. Luke B. The changing pattern of multiple births in the United States: maternal and infant characteristics, 1973 and 1990. Obstet Gynecol 1994;84:101-6.

5. Births in Great Britain resulting from assisted conception, 1978-87. MRC Working Party on children conceived by in-vitro fertilization. BMJ 1990; 300:1229-33.

6. McFaul PB, Patel N, Mills J. An audit of the obstetric outcome of 148 consecutive pregnancies from assisted conception: implications for neonatal services. $\mathrm{Br} \mathrm{J}$ Obstet Gynaecol 1993;100:820-5.

7. Working Party of the British Association for Perinatal Medicine and the College of Ophthalmologists. Screening for retinopathy of prematurity, 1990.

8. Arroe M, Peitersen B. Retinopathy of prematurity in a Danish neonatal intensive care unit, 1985-1991. Acta Ophthalmol (Copenh) 1993;210 (Suppl):37-40.

9. Barnekow BB, Stigman G. Retinopathy of prematurity in the southern part of Sweden. Acta Ophthalmol (Copenh) 1993;210 (Suppl):48-51.

10. Maly E. Frequency and natural history of retinopathy of prematurity: a prospective study in a Swedish city 1986-1990. Acta Ophthalmol (Copenh) 1993;210 (Suppl):52-5.

11. Palmer EA, Flynn JT, Hardy RJ, Phelps DL, Phillips CL, Shaffer DB, Tung B. Incidence and early course of retinopathy of prematurity. The Cryotherapy for Retinopathy of Prematurity Co-operative Group. Ophthalmology 1991;98:1628-40.

12. Ng YK, Fielder AR, Shaw DE, Levene MI. Epidemiology of retinopathy of prematurity. Lancet 1988;2:1235-8.

13. The Human Fertilization and Embryology Authority. List of Licensed Centres. February 1995.

14. Levene MI, Wild J, Steer P. Higher multiple births and the modern management of infertility in Britain. Br J Obstet Gynaecol 1992;99:607-13. 